\title{
Variable Pore Structure and Gas Permeability of Coal Cores after Microwave Irradiation
}

\author{
Yi-du Hong, ${ }^{1}$ Bai-quan Lin, ${ }^{2}$ Hua Xiang, ${ }^{3}$ Chuan-jie Zhu, ${ }^{2}$ Zheng Wang, ${ }^{2}$ and Wen Nie (iD) \\ ${ }^{1}$ Quanzhou Institute of Equipment Manufacturing, Haixi Institutes, Chinese Academy of Sciences, Quanzhou, Fujian 362000, China \\ ${ }^{2}$ School of Safety Engineering, China University of Mining and Technology, Xuzhou, Jiangsu 221116, China \\ ${ }^{3}$ Department of Offshore Oil and Gas Field Development, Faculty of Oil and Gas Field Development, Gubkin Russian State University \\ of Oil and Gas, Moscow 119991, Russia
}

Correspondence should be addressed to Wen Nie; wen.nie@fjirsm.ac.cn

Received 18 May 2018; Revised 25 July 2018; Accepted 18 September 2018; Published 6 December 2018

Academic Editor: Emanuele Tondi

Copyright (c) 2018 Yi-du Hong et al. This is an open access article distributed under the Creative Commons Attribution License, which permits unrestricted use, distribution, and reproduction in any medium, provided the original work is properly cited.

\begin{abstract}
The experimental work in this paper investigated the effect of microwave energy on pore structure and gas permeability of coal cores. Fifteen coal samples were irradiated under the condition of $2.45 \mathrm{GHz}$ with $6 \mathrm{~kW}$. The effect of microwave irradiation on the pore structure of coal samples was evaluated by nuclear magnetic resonance (NMR). The water saturation degree has little influence on transverse relaxation time $\left(T_{2}\right)$ distribution before the microwave treatment. By contrast, water saturation degree obviously affects the $T_{2}$ distribution after the microwave energy treatment. Coal permeability increased after microwave energy treatment. But fractal dimension decreased after microwave energy treatment. The results show that microwave energy has a potential for degassing coal seams.
\end{abstract}

\section{Introduction}

Gas permeability is an important parameter for coalbed methane $(\mathrm{CBM})$ production which could be affected by fracture and cleat apertures [1]. Currently, low permeability of coalbed limits the production and utilization of CBM, especially in China [2]. Furthermore, with mining depth in China increasing 10-25 $\mathrm{m}$ annually, the poor permeability and high CBM content phenomena become common [3]. Coal seams can be artificially fractured by several measures, such as hydraulic fracturing, hydraulic slotting, $\mathrm{CO}_{2}$ injection, and $\mathrm{N}_{2}$ injection, which can increase connectivity of fractures in coal seams for facilitating CBM extraction [4-9]. However, these methods may be not always effective when the coal seam has faults, caves, or large cracks penetrating the ground [10]. As a new degassing coal seam technology, formation microwave heating treatment (FMHT) is few limited by formation geology and is capable to distribute heat over a large reservoir volume thanks to the propagation of electromagnetic energy through the medium [11].
Selective heating nature of microwave would induce thermal stress at the interface between different materials with various dielectric constants [12]. Furthermore, poor thermal conductivity of coal matrix exacerbates the uneven temperature distribution resulting in thermal stress [13]. Thus, microwave energy would induce fractures and increase cleat apertures in the coal matrix [14]. In other words, the microwave energy treatment would influence the pore structure. Sahoo et al. confirmed micro cracks and fissures developed along grain boundaries under microwave irradiation [15]. Ruisanchez et al. found that thermal shock from microwave irradiation produces small cracks and microfissures in coke particle by microphotographs [16]. Liu et al. found that the surface of raw coal was complete and its structure was free of visible microfractures according to several SEM images [17]. Zhao et al. found that a large number of volatiles were released during microwave pyrolysis, which results in an increase in pore volume and specific surface area of lignite [18]. Ge et al. also indicate pore volume and surface area of low-rank coal increased after microwave irradiation treatment [19]. Wang et al. found that the specific surface area 
of lignite samples increases, average pore diameter and total pore volume decrease when microwave power increases from $400 \mathrm{~W}$ to $800 \mathrm{~W}$, and irradiation time increases from 4 to $16 \mathrm{~min}$ [20]. In our previous work, coal cores were collected from underground mines of Shenmu coalfield, China (the coal rank is gas coal), and were used to evaluate the effect of microwave irradiation on pore structure [21, 22]. The porosity, pore size, and pore number increased, but fractal dimensions decreased after microwave energy treatment. However, the effect of microwave energy treatment on gas permeability is still unclear. The permeability is physically significant for coalbed methane development. Therefore, it needs to pay more attention to research the microwave energy on gas permeability of coal.

Perera et al. found that there is a clear increase in gas permeability of naturally fractured black coal with increasing temperature for any confining pressure at high injection pressure (more than $10 \mathrm{MPa}$ ) [23]. And temperature does not affect permeability for injection pressure less than $9 \mathrm{MPa}$. Zhao et al. found gas permeability of coal cores changes a little during 20 to $300^{\circ} \mathrm{C}$ heating process but increases sharply during 300 to $600^{\circ} \mathrm{C}$ [24]. Li et al. found that gas permeability increased with temperature when thermal stress was greater than effective stress [25]. Feng et al. found that gas permeability of anthracite decreased at first then increased and finally decreased again with temperature increasing [26]. Wu et al. found that the increased temperature can induce a series of results, such as promoting gas desorption, enhancing gas slippage effect, and inducing coal matrix thermal swelling, resulting in decomposition [27]. And all of those can affect the gas permeability of coal further.

However, investigations of effect of microwave energy on coal gas permeability are not sufficient to provide guidance for FMHT application in field $[28,29]$. The main objective of this study is to investigate the effect of microwave energy on the pore structure and gas permeability of coal cores by experiments. Nuclear magnetic resonance (NMR) measurement and permeability test was carried out to evaluate the effect of microwave energy processing on pore structure and gas permeability. In addition, the effect of water saturation degree on transverse relaxation time $\left(T_{2}\right)$ distribution was investigated.

\section{Experimental Methodology}

2.1. Coal Samples. Fifteen natural coal cores ( $25 \mathrm{~mm}$ in diameter and $60 \mathrm{~mm}$ in height) were collected from Yuanzhuang coal mine, Huaibei, China (the coal rank is $1 / 3$ coking coal, which is different with the coal in $[21,22])$. Several lump coals were obtained from the working face and immediately sent to the laboratory for experiments. Proximate analysis of coal was accomplished according to the Chinese Coal Proximate Analysis Standard GB/T 212-2008. Maximum vitrinite reflectance of the three coal samples in oil (room temperature, $23^{\circ} \mathrm{C}$ ) was measured. Coal maceral compositions are as shown in Table 1. The coal cores were treated by a microwave heating system (Figure 1). Pore structure of coal cores was measured by an NMR
TABLE 1: Proximate analysis and maximum vitrinite reflectance of coal samples.

\begin{tabular}{lccccc}
\hline Coal & $\mathrm{R}_{\text {omax }} / \%$ & $\mathrm{M}_{\mathrm{ad}} / \%$ & $\mathrm{~A}_{\mathrm{ad}} / \%$ & $\mathrm{~V}_{\mathrm{ad}} / \%$ & $\mathrm{Fc}_{\mathrm{ad}} / \%$ \\
\hline HY & 0.9190 & 2.56 & 12.10 & 32.75 & 52.59 \\
\hline
\end{tabular}

Notes: $\mathrm{R}_{\text {omax }}$ is the maximum vitrinite reflectance; $\mathrm{M}$ is the moisture; $\mathrm{A}$ is the ash; $\mathrm{V}$ is the volatile matter; $\mathrm{Fc}$ is the fixed carbon; ad is the air-dry basis.

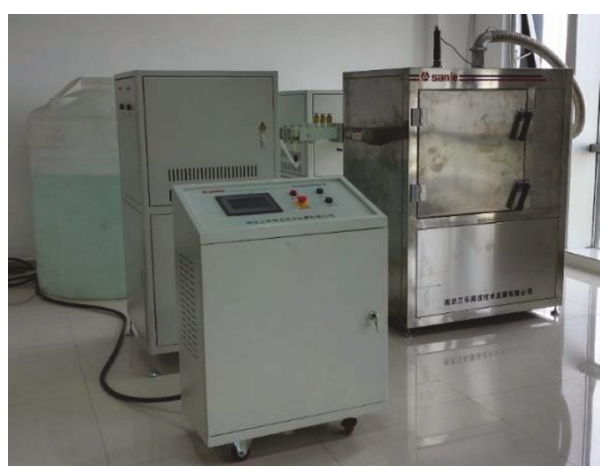

FIGURE 1: Microwave heating system.

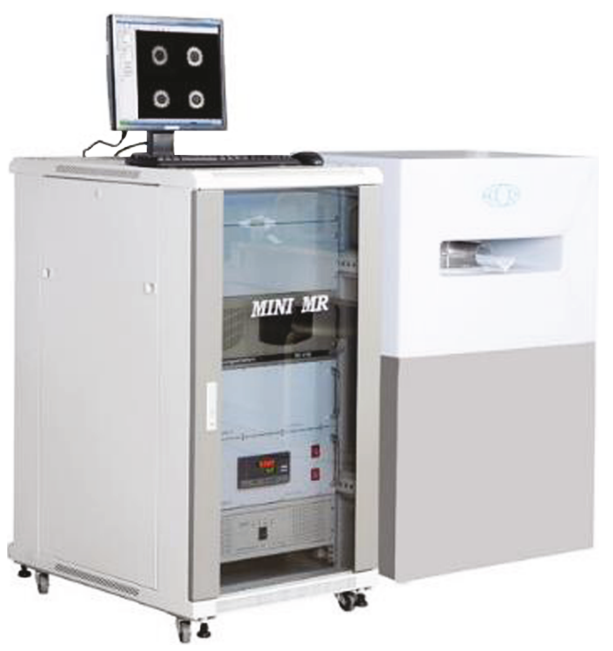

Figure 2: Low-field nuclear magnet resonance.

instrument (Figure 2). And the coal porosity was carried out by a gravimetric method.

2.2. Microwave Heating System. A novel microwave heating system (Figure 1) was carried out to heat coal cores. Microwave frequency is $2450 \pm 25 \mathrm{MHz}$ and microwave power is $6 \mathrm{~kW}$ in this study. In general, thermal decomposition does not occur when the temperature is lower than $200^{\circ} \mathrm{C}$ [30]. Thus, the processing temperature varies from 50 to $200^{\circ} \mathrm{C}$. The basic parameter and processing temperature of coal cores are as shown in Table 2.

2.3. NMR Measurements. A nondestructive approach, nuclear magnetic resonance (NMR) measurement, was carried out to evaluate the effect of microwave energy on the pore structure 
TABLE 2: Basic parameters and processing temperature of coal samples.

\begin{tabular}{lccccccc}
\hline Sample ID & $d / \mathrm{mm}$ & $h / \mathrm{mm}$ & $T /{ }^{\circ} \mathrm{C}$ & Sample ID & $d / \mathrm{mm}$ & \multicolumn{2}{c}{$\mathrm{T} / \mathrm{mm}^{\circ} \mathrm{C}$} \\
\hline HY-01 & 24.2 & 63.0 & 50 & HY-09 & 24.3 & 62.1 & 50 \\
HY-02 & 24.4 & 62.4 & 100 & HY-10 & 24.1 & 50 \\
HY-03 & 24.2 & 62.6 & 150 & HY-11 & 24.2 & 59.7 & 100 \\
HY-04 & 24.3 & 61.3 & 200 & HY-12 & 24.1 & 61.1 \\
HY-05 & 24.4 & 62.1 & 50 & HY-13 & 24.2 & 60.4 \\
HY-06 & 24.3 & 60.4 & 100 & HY-14* & 24.2 & 60.7 \\
HY-07 & 25.0 & 61.0 & 150 & HY-15* & 24.2 & 61.6 \\
HY-08 & 24.3 & 62.2 & 200 & & & - \\
\hline
\end{tabular}

Notes: $d$ is diameter of coal cores; $h$ is height of coal cores; $T$ is the processing temperature; ${ }^{\#}$ this sample was broken into three pieces after microwave treatment; *these two samples are not treated by microwave irradiation.

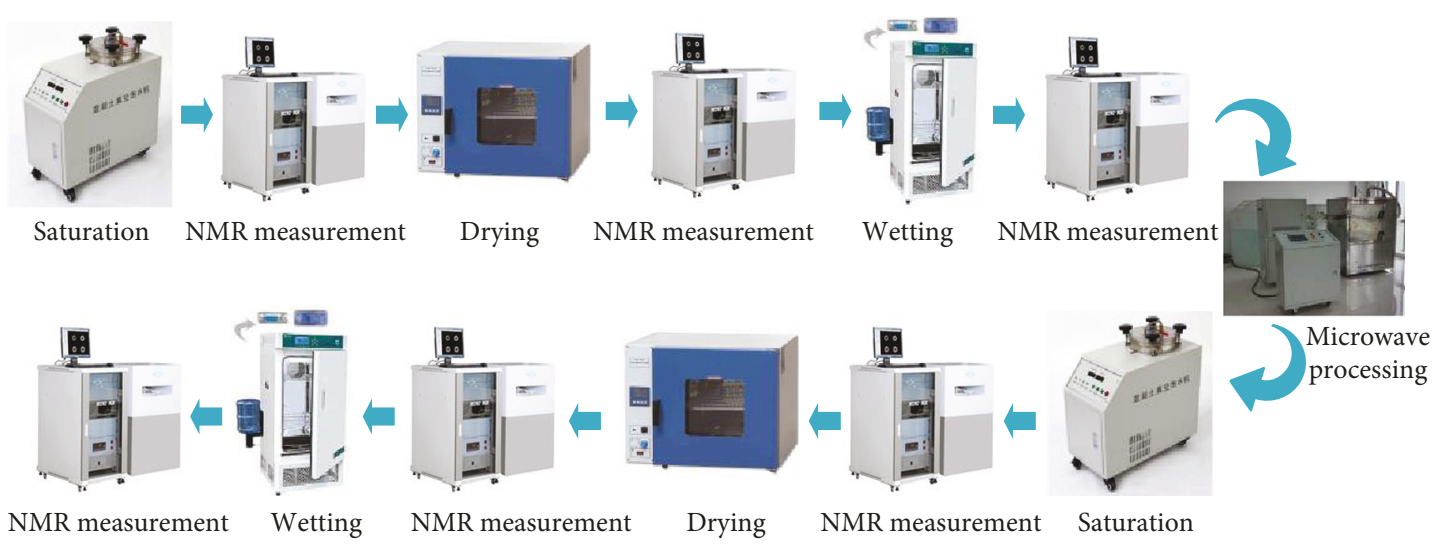

FIGURE 3: Experimental procedure for NMR measurement.

of coal cores. NMR utilizes an external magnetic field to align hydrogenous fluid component of the sample and presents number of hydrogen atoms by the amplitude of the dipole moment [31]. Therefore, it is a measurement of the water volume in the pore structure. NMR has been widely used for the characterization of complex porous media, such as the petroleum reservoir rocks and coal [32-36]. For example, a recent research by Zhang et al. demonstrated that the successful use of the NMR to obtain pore size distribution of mudrock and fine-grained sandstone samples [37]. When the magnetic field is small, few paramagnetic minerals within the coal could influence the measured results and the magnetic information on solid state proton $\left({ }_{13} \mathrm{C}\right.$ and $\left.{ }_{1} \mathrm{H}\right)$ can be shielded $[31,38]$. The longitudinal $\left(T_{1}\right)$ and transverse $\left(T_{2}\right)$ relaxation time can be used to characterize the pore distribution. $T_{2}$ is the preferred measurement method because the measurement of $T_{2}$ is fast and usually provides similar results with respect to $T_{1}$ [39]. The $T_{2}$ relaxation time can be interpreted as follows [40]:

$$
\frac{1}{T_{2}}=\frac{1}{T_{2 \mathrm{~B}}}+\rho\left(\frac{S}{V}\right)+\frac{D\left(\gamma G T_{\mathrm{E}}\right)^{2}}{12},
$$

where $T_{2 \mathrm{~B}}$ is the free relaxation time, ms; $\rho$ is a constant representing the transverse relaxation strength, $\mu \mathrm{m} / \mathrm{ms}$; $S / V$ is the specific surface area which relates to the pore size;
$D$ is the diffusion coefficient, $\mu \mathrm{m}^{2} / \mathrm{ms} ; \gamma$ is the gyromagnetic ratio, $\mathrm{MHz} / \mathrm{T}$; and $G$ is the field-strength gradient, $\mathrm{Gs} / \mathrm{cm}$; $T_{\mathrm{E}}$ is the interecho spacing, ms.

Since the value of $T_{2 \mathrm{~B}}$ is always much larger than $T_{2}$, i.e., $\left(1 / T_{2}\right) \gg\left(1 / T_{2 B}\right)$, and the values of $D$ and $T_{\mathrm{E}}$ are always small, (1) can be simplified as shown below [33, 41]:

$$
\frac{1}{T_{2}}=\rho\left(\frac{S}{V}\right)
$$

$T_{2}$ distribution in smaller pores relaxes faster than that in larger pores [40]. Therefore, $T_{2}$ distribution is similar to the pore size distribution. Larger pores mean longer relaxation time while smaller pores produce shorter relaxation time.

A MINI MR instrument manufactured by the Shanghai Niumag Corporation (China) (Figure 2) was used to carry out the NMR measurements. Constant magnetic field strength of this instrument is $0.53 \mathrm{~T}$, while resonance frequency is $23 \mathrm{MHz}$ and constant temperature is $32^{\circ} \mathrm{C}$. The measurement parameters include the following: interecho spacing, $0.23 \mathrm{~ms}$; the number of scans, 32; and sampling frequency, $333.33 \mathrm{KHz}$. Then, transverse relaxation time $\left(T_{2}\right)$ distributions were computed by the simultaneous iterative reconstruction technique with 100,000 iterations [42].

NMR measurement procedures were carried out according to Figure 3. "Saturation" means that coal samples were 

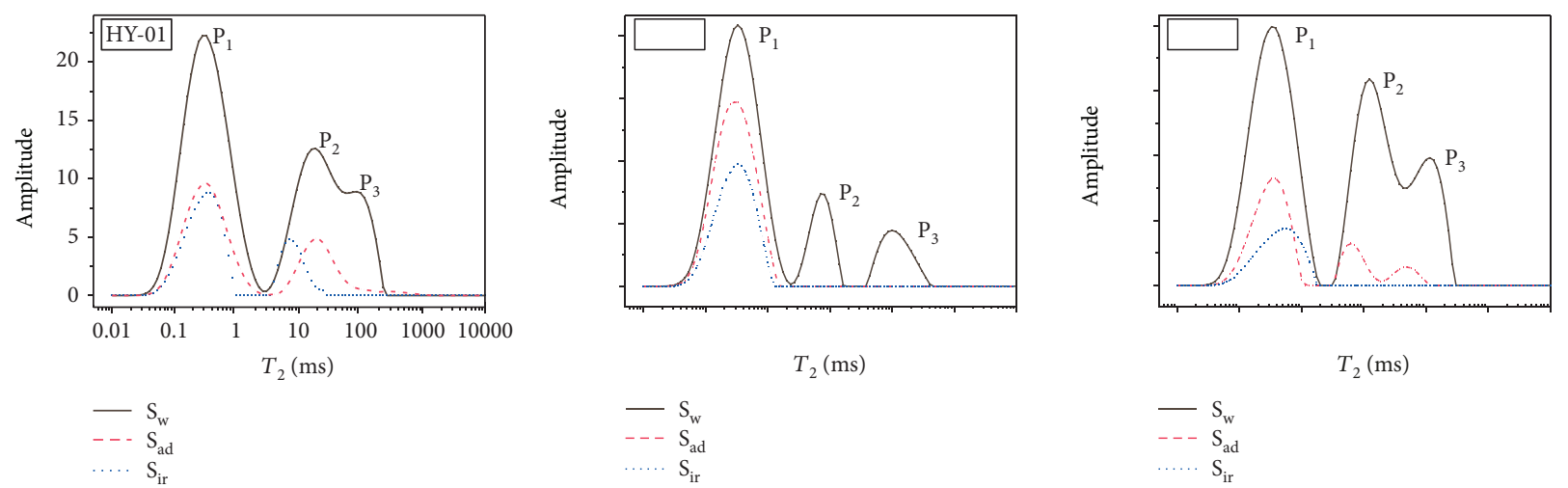

(a)

(b)
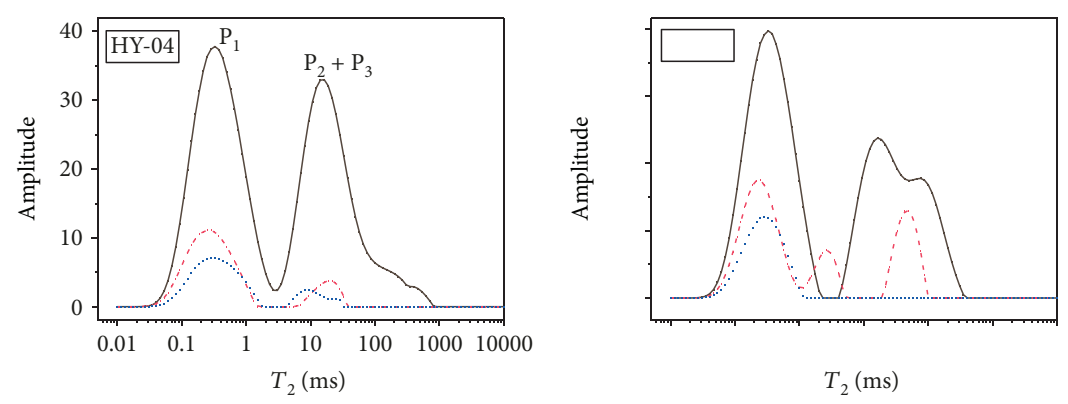

(c)

$$
\begin{aligned}
& -\mathrm{S}_{\mathrm{w}} \\
& --\mathrm{S}_{\mathrm{ad}} \\
& \ldots . \mathrm{S} \mathrm{S}_{\mathrm{r}}
\end{aligned}
$$$$
\begin{aligned}
& -S_{\mathrm{w}} \\
& -.-S_{\mathrm{ad}} \\
& \ldots . . . \mathrm{S}_{\mathrm{rr}}
\end{aligned}
$$

(d)

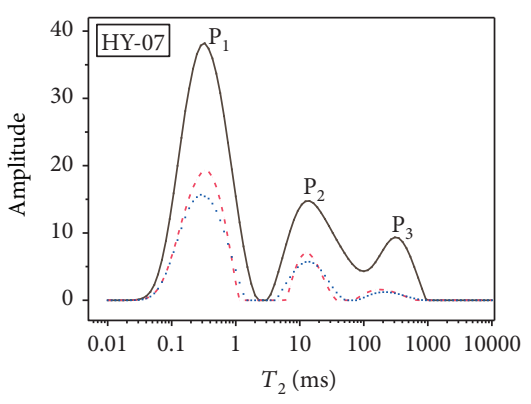

(e)

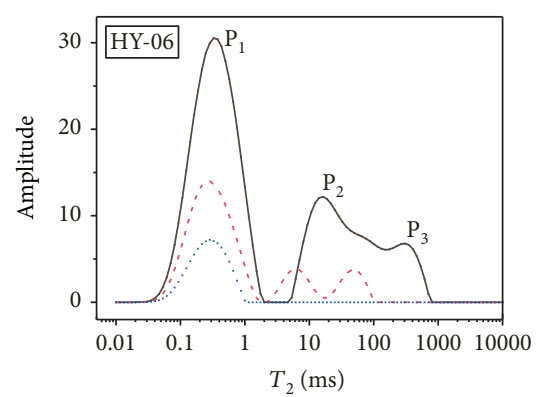

$$
\begin{aligned}
& -\mathrm{S}_{\mathrm{w}} \\
& -\cdots \mathrm{S}_{\mathrm{ad}} \\
& \ldots . \mathrm{S}_{\mathrm{ir}}
\end{aligned}
$$

e)

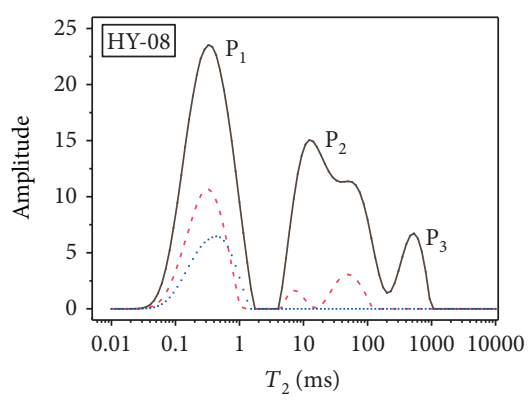

(f)

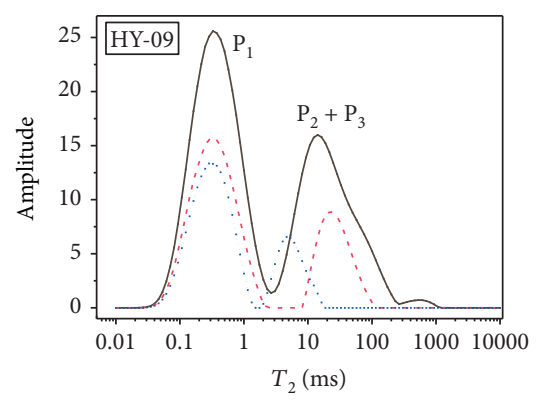

$$
\begin{aligned}
& -S_{\mathrm{w}} \\
& -\cdots \mathrm{S}_{\mathrm{ad}} \\
& \ldots . \mathrm{S}_{\mathrm{ir}}
\end{aligned}
$$

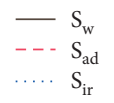

(h)

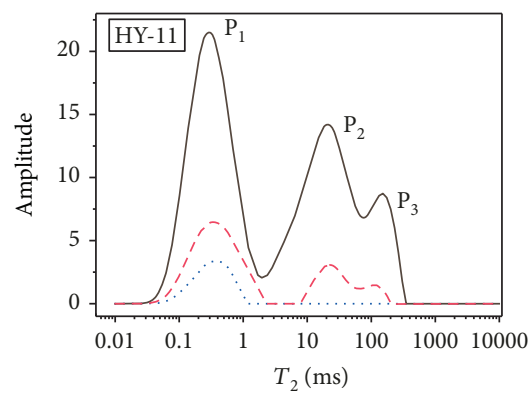

(i)

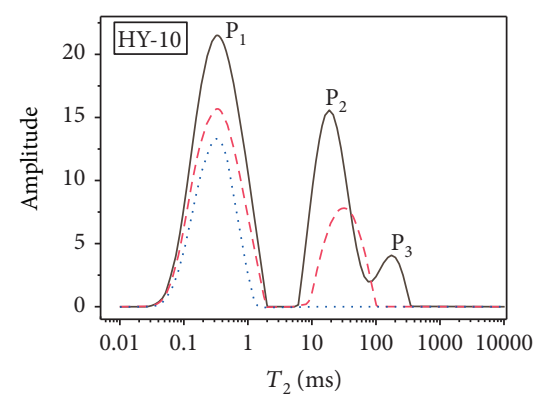

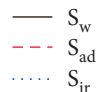

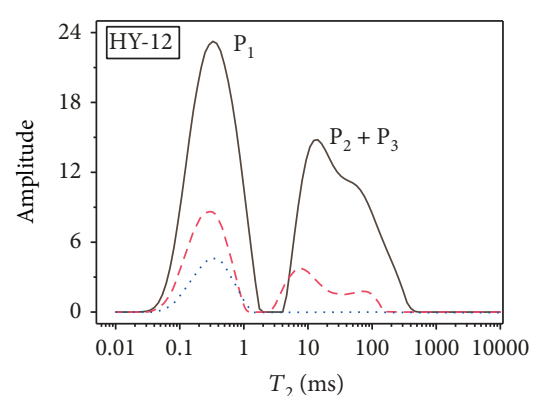

$-S_{\mathrm{w}}$
$\ldots \mathrm{S}_{\mathrm{ad}}$
$\ldots . \mathrm{S}_{\mathrm{ir}}$

Figure 4: Continued. 


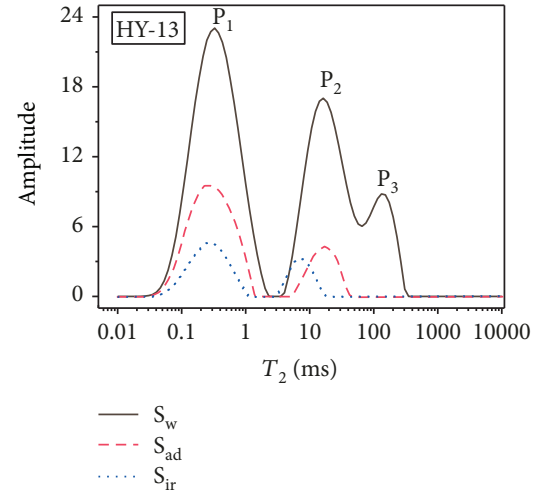

$(\mathrm{m})$

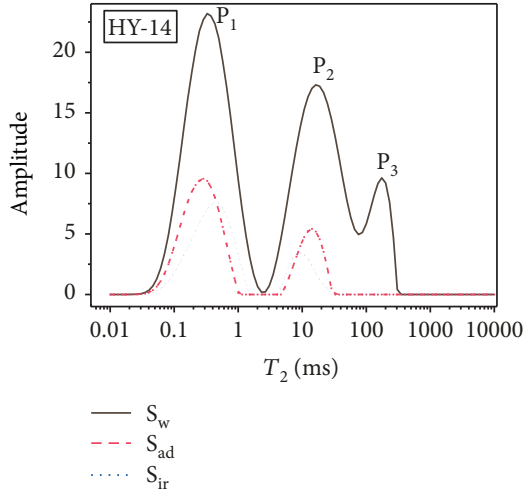

(n)

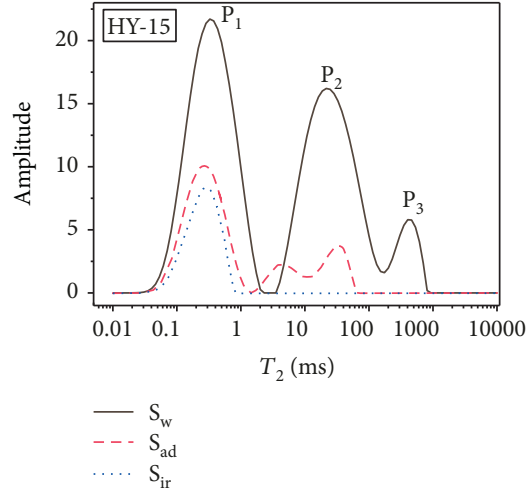

(o)

FIGURE 4: NMR $T_{2}$ distribution before microwave treatment with various water saturation.

saturated with $100 \%$ distilled water for at least 72 hours. The $T_{2}$ spectrum at "drying" shows that coal samples were dried for 24 hours in a vacuum furnace at $40^{\circ} \mathrm{C}$ with absolute pressure $\sim 8 \mathrm{kpa}$. "Wetting" means that coal samples were processing with $\sim 20^{\circ} \mathrm{C}$ and $100 \%$ humidity for 24 hours. "NMR measurement" shows that coal samples were measured by the NMR instrument. "Microwave processing" is that coal samples are heated by the microwave heating system. The NMR measurements were carried out after "saturation" $\left(S_{\mathrm{w}}\right)$, "drying" $\left(S_{\text {ir }}\right)$, and "wetting" $\left(S_{\text {ad }}\right)$ processing.

In addition, the permeability test was carried out after all NMR measurement. Anhydrous copper sulphate dried coal cores under ambient temperature $\sim 25^{\circ} \mathrm{C}$ for 24 hours before the permeability test. The test gas is nitrogen and the lateral confining pressures are $3 \mathrm{MPa}$ and $10 \mathrm{MPa}$ for gas permeability measurement, respectively. In this test, the temperature is ambient temperature $\left(\sim 25^{\circ} \mathrm{C}\right)$. And the permeability test carried out under an initial lateral confining pressure $3 \mathrm{MPa}$.

\section{Experiment Results}

NMR measurements of fifteen coal cores with various water saturation degrees were performed before microwave treatment (Figure 4). Black solid lines are $T_{2}$ spectra at $S_{w}$, while red dash lines are $T_{2}$ spectra at $S_{\text {ad }}$ and blue dash lines are $T_{2}$ spectra at $S_{\mathrm{ir}}$. Wave trough can be used to separate the peaks. So distribution of the $T_{2}$ spectra at $S_{\mathrm{w}}$ is commonly three peaks, $p_{1}$ at $0.03-3 \mathrm{~ms}, \mathrm{p}_{2}$ at $3-100 \mathrm{~ms}$, and $\mathrm{p}_{3}$ at $>100 \mathrm{~ms}$ (Figure 4 ). The two peaks will be regarded as a new peak if without clear wave trough [21]. For example, in sample HY-04 (Figure 4(d)), the wave through between $\mathrm{p}_{2}$ and $\mathrm{p}_{3}$ is not clear. So the two peaks can be considered as a new peak $\left(\mathrm{p}_{2}+\mathrm{p}_{3}\right)$. For multiple peaks, the amplitude of the wave trough between peaks can be used to identify the connection among pores [31]. Take HY-011 as example (Figure $4(\mathrm{~g})$ ), the amplitude of wave troughs between three peaks is much larger than zero, which suggests wellconnected multipores exist in this coal sample. However, in HY-02 (Figure 4(b)), the amplitude of wave troughs between three peaks is equal to zero. This indicates that the pore connection is bad.
$S_{\mathrm{w}}$ means coal core processing by "saturation," $S_{\mathrm{ir}}$ means processing by "drying," and $S_{\mathrm{ad}}$ means processing by "wetting."

The effect of water saturation degree on $T_{2}$ distribution is obviously after the microwave energy treatment (Figure 5). Taking HY-01 as an example, the second peak (from left to right) of $T_{2}$ distribution at $S_{\text {ir }}$ locates at the left hand of the $\mathrm{T}_{2}$ distributions at $S_{\mathrm{ad}}$ (Figure 5(a)). This is consistent with our previous work [21, 22].

Permeability of twelve coal samples (HY-04, HY-09, and HY-13 deformed after microwave energy treatment) was measured (Figure 6(a)). HY-14 and HY-15 represent the coal permeability without microwave energy treatment. Ambient temperature is $25^{\circ} \mathrm{C}$ in this study, and therefore, the temperature of untreated coal samples is marked as $25^{\circ} \mathrm{C}$. The coal permeability increases with increased processing temperature (Figure 6(a)). This indicates that microwave energy treatment improved pore connectivity of coal. The connectivity of pore is main factor which affects the permeability of coal [43]. In general, permeability of coal sample decrease exponentially with the increase of effective stress [44]. In this study, with lateral confining pressure increase from $3 \mathrm{MPa}$ to $10 \mathrm{MPa}$, the permeability decreases. But the permeability of coal samples treated is still higher than that of coal samples untreated under $10 \mathrm{MPa}$ confining pressure.

\section{Discussions}

4.1. $T_{2}$ Distribution of Coal Cores. Moisture in pore structure always can be divided into four types: free moisture, capillary moisture, chemically bound moisture, and water of hydration [45]. Chemically bound moisture and water of hydration are difficult to remove. Free moisture would not completely evaporate until $110^{\circ} \mathrm{C}$, and capillary moisture would completely evaporate when temperature exceeds to $180^{\circ} \mathrm{C}$ with atmospheric pressure [46, 47]. The water boiling temperature is $40^{\circ} \mathrm{C}$ at absolute pressure $\sim 8 \mathrm{kpa}$. Thus, the free moisture can mostly be removed after "drying" processing. The $T_{2}$ spectra at $S_{\text {ir }}$ may only indicate capillary moisture, chemically bound moisture, water of hydration, and a little part of free moisture in the pore structure. And the water saturation degree at $S_{\mathrm{ir}}$ is lower than that of $S_{\mathrm{ad}}$. Therefore, the 

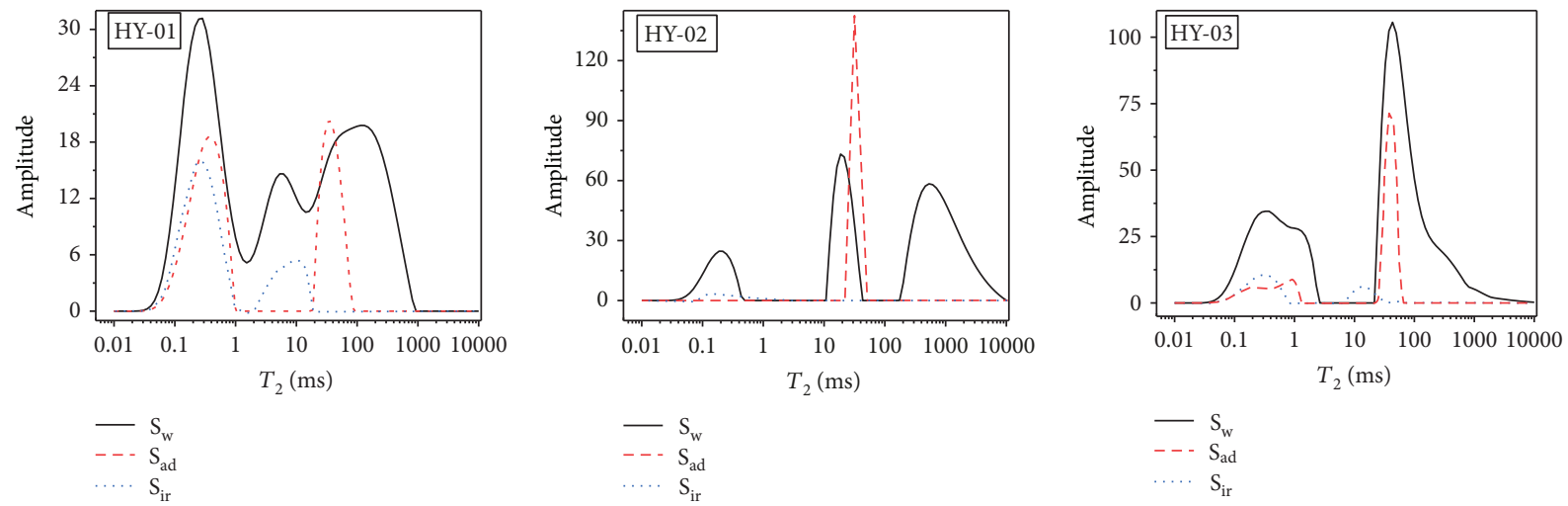

(b)
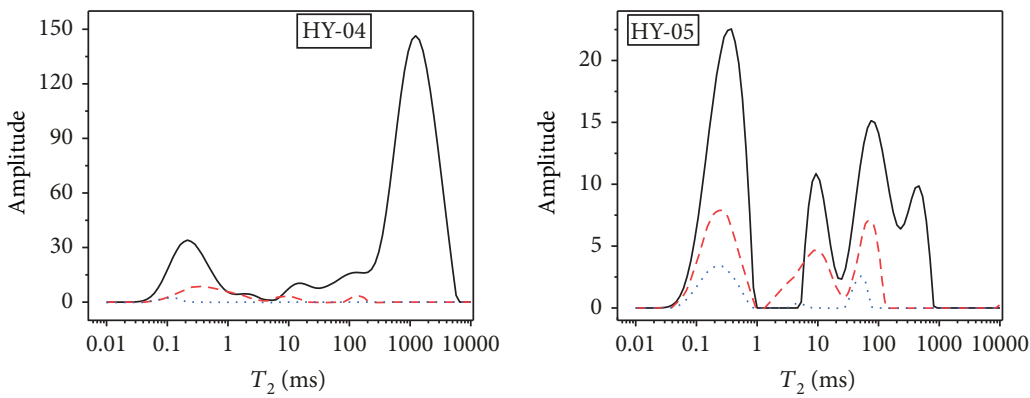

(c)

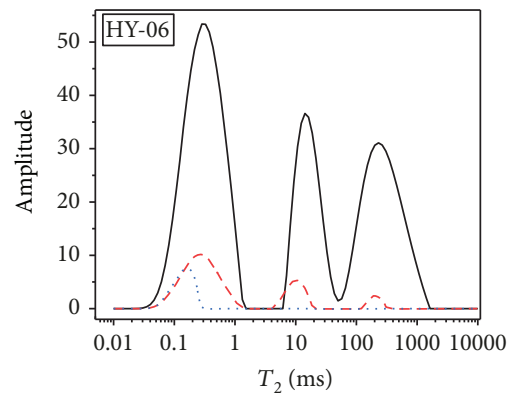

$\begin{array}{ll}-S_{\mathrm{w}} \\ --\cdot S_{\mathrm{ad}} \\ \cdots & S_{\text {ir }}\end{array}$

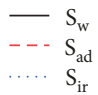

$-S_{\mathrm{w}}$

… $\mathrm{S}_{\mathrm{ir}}$

(d)

(e)
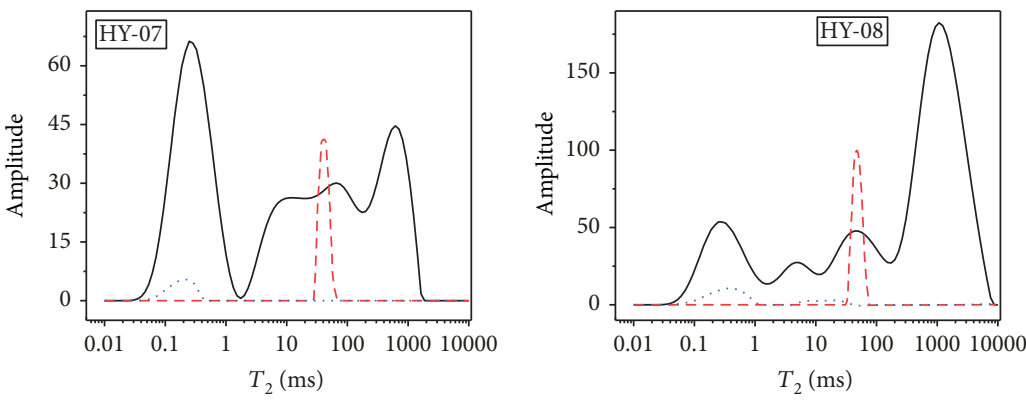

(f)

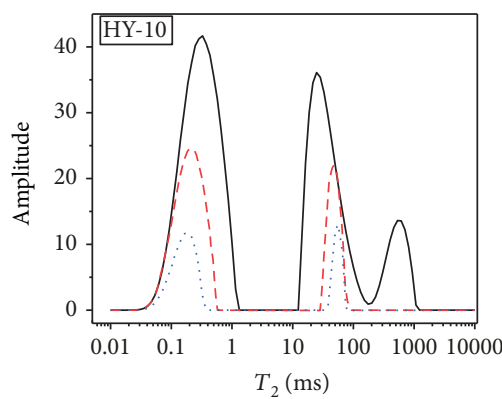

$-S_{w}$

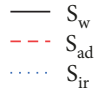

$\begin{array}{ll}-S_{w} \\ --- & S_{a d}\end{array}$

..... $S_{\text {ir }}$

(h)

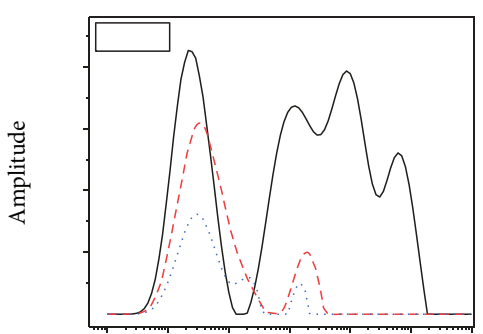

$T_{2}$ (ms)

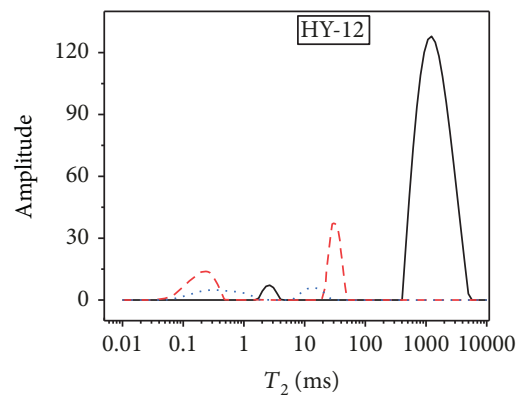

(i)

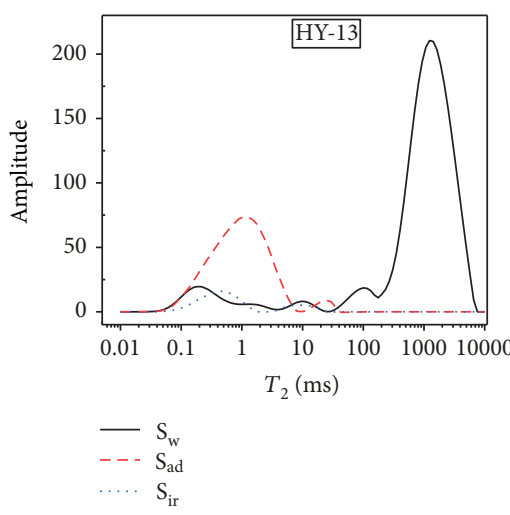

(l)

FIGURE 5: NMR $T_{2}$ distribution after microwave treatment with various water saturation. 


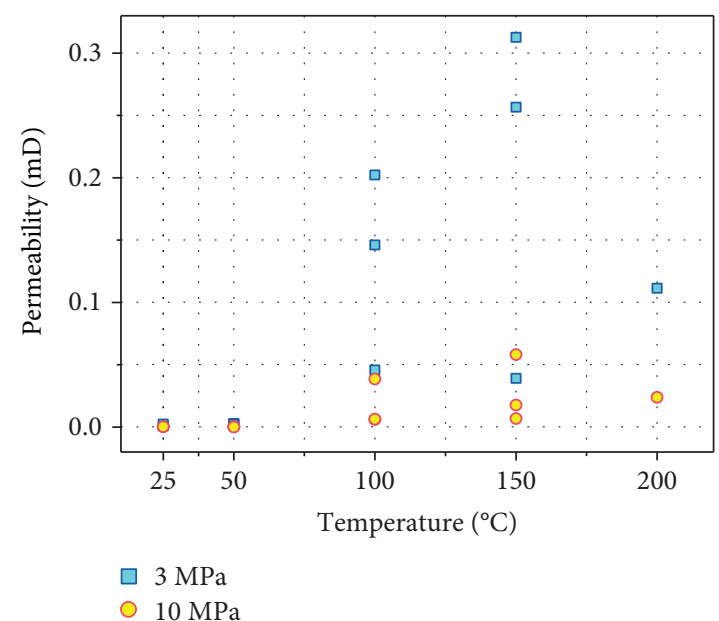

(a)

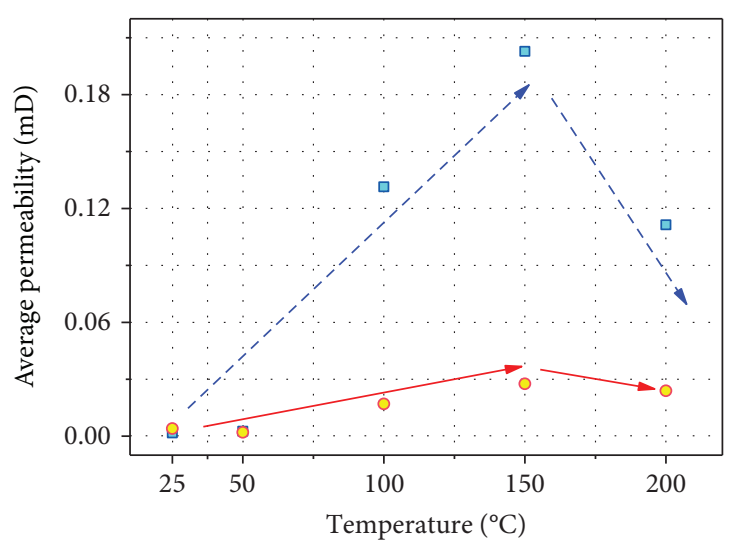

$\square 3 \mathrm{MPa}$

○ $10 \mathrm{MPa}$

FIGURE 6: Effect of microwave treatment on coal permeability.

number and amplitude of peaks of $T_{2}$ spectra at $S_{\text {ad }}$ is larger than that of $S_{\text {ir }}$ (Figure 4).

Although the amplitude of $T_{2}$ distribution decreases with decreasing water saturation degree, the water saturation degree has little influence on $T_{2}$ distribution location (before microwave treatment) (Figure 4). This is different to our previous work that the $T_{2}$ distributions at $S_{\text {ir }}$ and $S_{\text {ad }}$ were located at the left-hand side of the $T_{2}$ distributions at $S_{\mathrm{w}}$ $[21,22]$. The reason could be the differences of the pore structure and wettability of coal. The pore structure (including volume, specific surface area, and pore connectivity) relates to coal ranks $[31,48,49]$. The rank of coal used in this study differs from that in our previous work. Thus, the water distribution in pore structure of the coal used in this study is different. Furthermore, the composition of mineral and functional groups relates to coal ranks [50], which affects the wettability and hydrophobicity of coal surface [51]. And the pores in coal are not simple geometrical shapes such as cylinders or shapes. The pore walls may be rough and the pore may contain many tiny irregularities. And the wettability of coal decreases with the increase of surface roughness [21]. Thus, the microporosity on the pore walls containing water depends on the wettability of coal pore surface. In NMR measurement, all pore space of the water molecules of the pore fluid diffuse before relaxing by interacting with the pore walls would be regarded as a single pore. Thus, the microporosity contained in the rough pore surface and in the irregularities will often be included by NMR measurement as part of the total volume of the large pore [40]. Therefore, the microporosity may appear in larger relaxation time of the $T_{2}$ distribution at $S_{\mathrm{w}}$. Moreover, the microporosity contained in the rough surface may not contain water caused by high surface roughness or low wettability. The pore structure and wettability of coal would affect the $T_{2}$ distribution.

The area under the $T_{2}$ distribution curve is proportional to the number of hydrogen protons in the pore fluids within the pore structure [40]. Therefore, the area of $T_{2}$ distribution can be calibrated to give a porosity value. The area under the

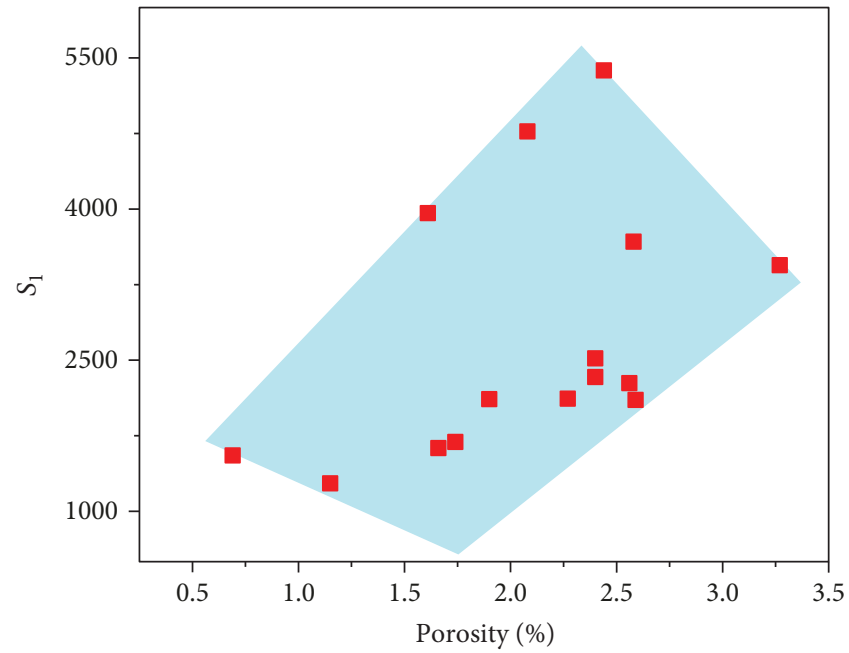

FIgURE 7: Relation between $S_{1}$ and porosity. $S_{1}$ is the area under the $\mathrm{T}_{2}$ distribution curve of coal cores without microwave processing.

$T_{2}$ distribution curve $\left(S_{1}\right)$ increases with increased porosity (Figure 7). It should be noted that the porosity here is the porosity of coal sample without microwave energy treatment. The linear relation between the area of $T_{2}$ distribution and porosity is not obvious. The reason may be the heterogenetic of coal samples. The extraction of lump coal is usually extremely sparse compared to the volume of coal seams. Moreover, cores are more easily taken from well-consolidated part in lump coal.

4.2. Effect of Microwave Energy on $T_{2}$ Distributions. This suggests that the pore structure and wettability of coal is influenced by microwave energy treatment. In general, thermal decomposition does not occur when the temperature is lower than $200^{\circ} \mathrm{C}$ [30]. In this study, the maximum processing temperature is $200^{\circ} \mathrm{C}$. Thus, there is no thermal 


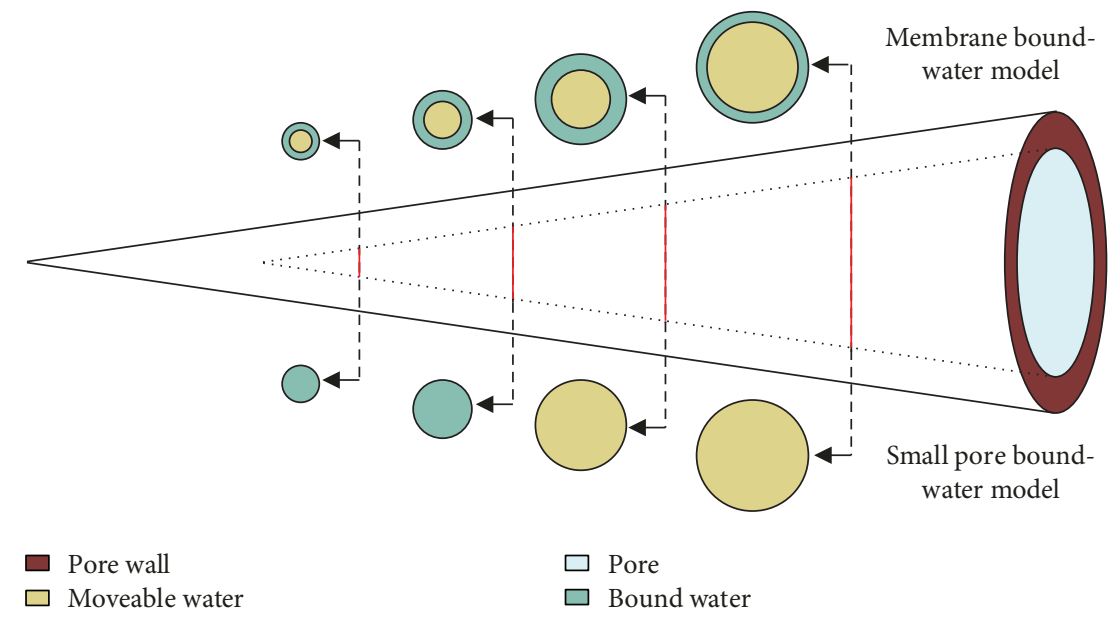

FIGURE 8: NMR bound-water model.

decomposition in the coal cores, which means the coal rank would not change after microwave energy treatment. The thermal fracture results from the different microwaveabsorbing properties or a different dielectric permittivity and loss factor of each phase [12]. Moreover, the microwave energy treatment would influence the pore surface roughness of coal, which may affect the wettability [21]. Therefore, the effect of water saturation degree on $T_{2}$ distribution is different pre- and postmicrowave.

Small pore bound-water (SPBW) model and membrane bound-water (MBW) model are always used to describe the state of bound water in pore structure (Figure 8) [22]. SPBW is based on the assumption that the free fluids reside in large pores and the bound fluids reside in small pores, while MBW believes that a given pore can contain both free and bound fluids [22]. As Figure 5 shows, the water saturation degree can influence $T_{2}$ distribution. This suggests that MBW model may be more suitable to describe the state of bound water. This is consistent with our previous work [21, 22].

$T_{2}$ distribution at $S_{\mathrm{w}}$ changes after microwave processing (Figure 9). According to the amplitude changing, these spectra can be divided into several cases. First, the amplitude of $T_{2}$ distribution at $S_{\mathrm{w}}$ of treated samples is larger that of untreated samples at all spectra (such as Figure 9(a), 9(g), and 9(h)). Second, not all amplitude of the spectra becomes larger after microwave treatment (such as Figure 9(d) and 9(l)). In this case, the amplitude of the spectra decreases after microwave treatment when $T_{2}$ is less than $100 \mathrm{~ms}$. Microwave energy treatment can induce fractures and increase pore sizes. Moreover, the microporosity contained in the rough pore surface and in the irregularities will often be regarded as part of the total volume of the large pore in NMR measurement [40]. Thus, a majority of microporosity cannot appear in $T_{2}$ distribution at $S_{\mathrm{w}}$ of treated coal samples. This confirmed the MBW model is more suitable to describe the state of bound water in coal. According (2), the changing of $T_{2}$ distribution at $S_{\mathrm{w}}$ also suggests that the specific surface area of the coal sample changed after microwave treatment.
The surface integral of $T_{2}$ distribution at $S_{\mathrm{w}}$ can be used to characterize the pore system because of the abscissa of the $T_{2}$ distribution representing the pore size and the ordinate representing the pore number $[21,30,38]$. A dimensionless parameter $\left(R_{\mathrm{s}}\right)$ was used to evaluate the effect of microwave energy treatment on coal samples, which can be defined as

$$
R_{\mathrm{s}}=\frac{S_{2}-S_{1}}{S_{1}}
$$

where $S_{1}$ is a curved surface integral of the $T_{2}$ distribution at $S_{\mathrm{w}}$ before microwave energy treatment and $S_{2}$ is a curved surface integral of the $T_{2}$ distribution at $S_{\mathrm{w}}$ after microwave energy treatment.

$R_{\mathrm{s}}$ increases with increasing processing temperature (Figure 10). This suggests that the pore volume increases with processing temperature. This also confirmed that microwave energy treatment would induce fractures. This is consistent with our previous work that the porosity increases after microwave heating [21].

4.3. Gas Permeability of Coal Cores Pre- and Postmicrowave. The influence of processing temperature on average permeability is evaluated (Figure 6(a)). HY-04 and HY-13 deformed after microwave energy treatment and cannot be carried out in the gas permeability test. Thus, permeability of HY-08 was used to present the average permeability of coal samples at $200^{\circ} \mathrm{C}$. The average permeability increases at first then decreases with incremental processing temperature (the turning point is $150^{\circ} \mathrm{C}$ ). This is different from the work by $\mathrm{Li}$, who found that the permeability decreases at first then increases and finally decreases again with temperature increasing $\left(25-180^{\circ} \mathrm{C}\right)$ under lateral confining pressure $6 \mathrm{MPa}$ [52]. The coal matrix would produce thermal expansion resulting in pore space shrink, which would induce permeability decreasing. But with the processing temperature increasing, the thermal expansion may induce coal matrix fracturing. Thus, pore space increased would result in the permeability increasing. Furthermore, fractures in coal matrix 


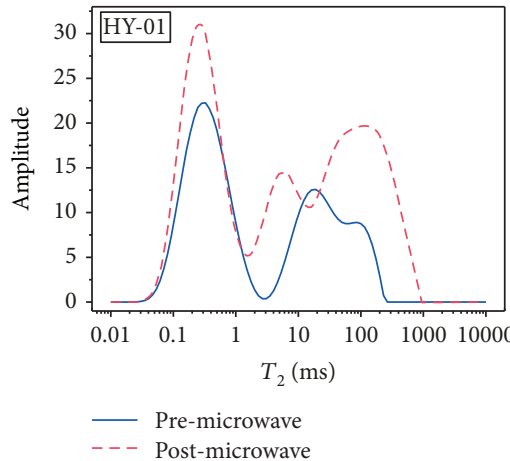

(a)

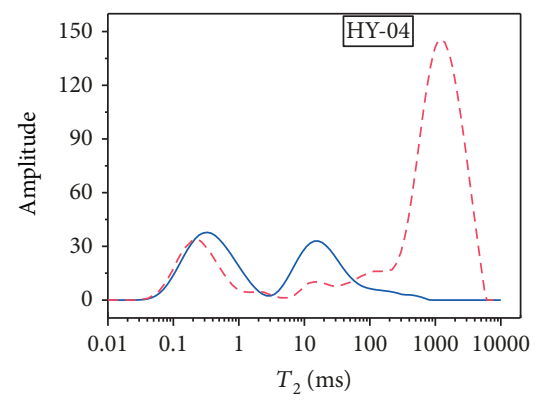

- Pre-microwave - - - Post-microwave

(d)

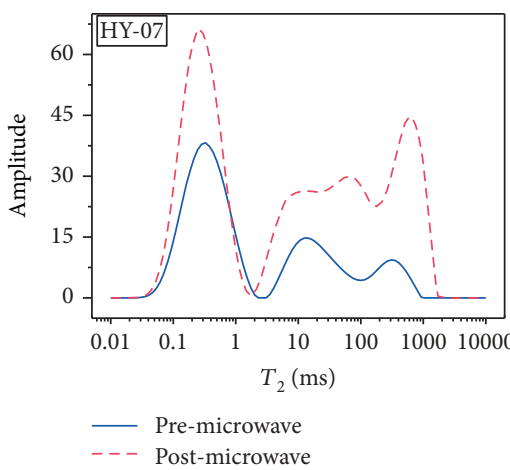

(g)

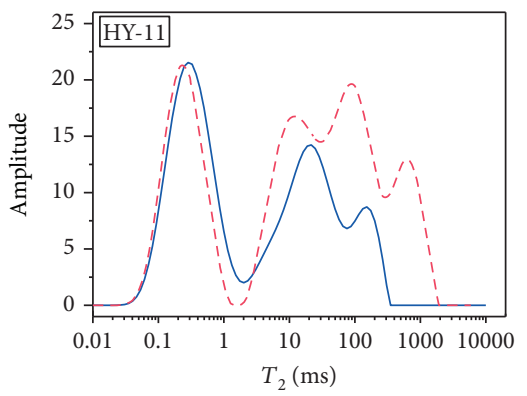

Pre-microwave

(j)

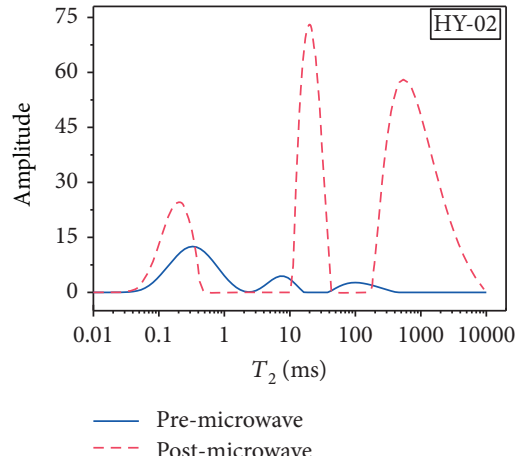

(b)

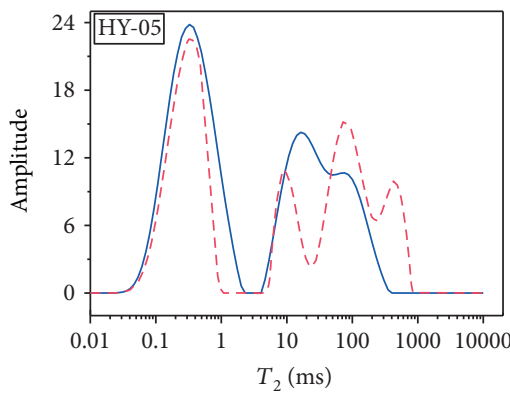

- Pre-microwave

(e)

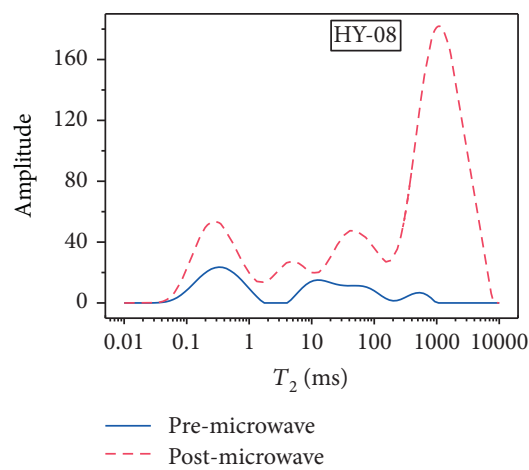

(h)

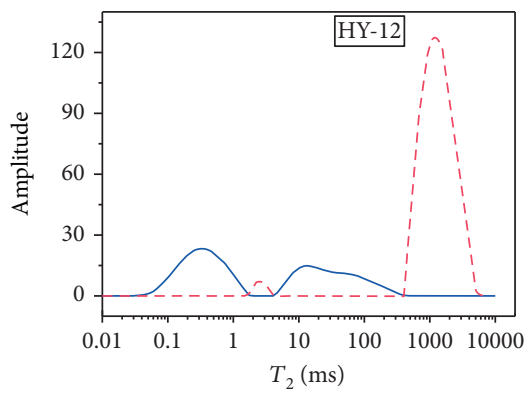

$\begin{array}{ll}\text { - } & \text { Pre-microwave } \\ \text { - - } & \text { Post-microwave }\end{array}$

(k)

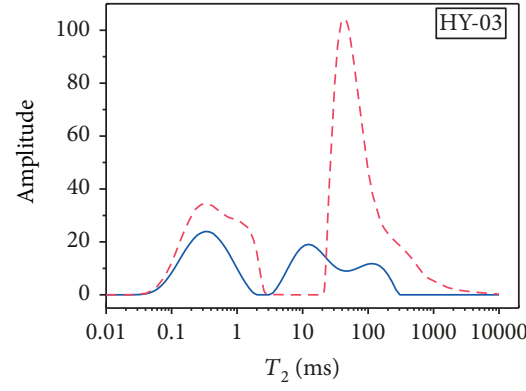

— Pre-microwave

- - - Post-microwave

(c)

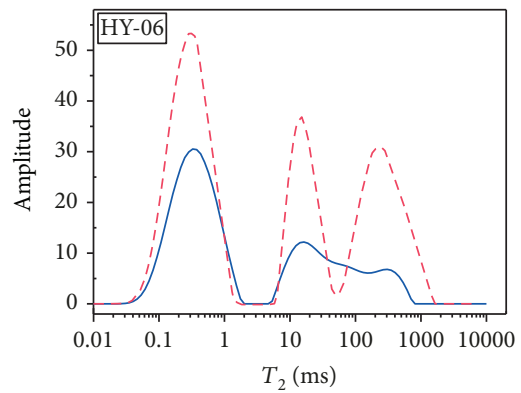

- Pre-microwave

- - Post-microwave

(f)

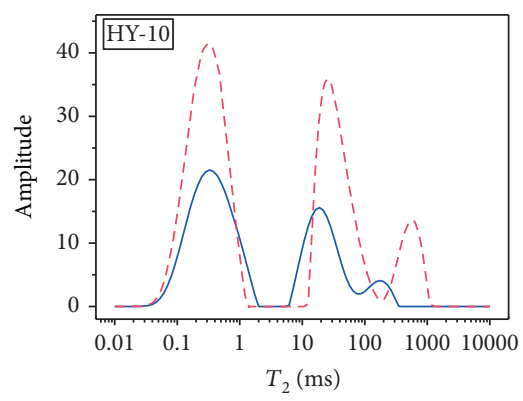

_ Pre-microwave

(i)

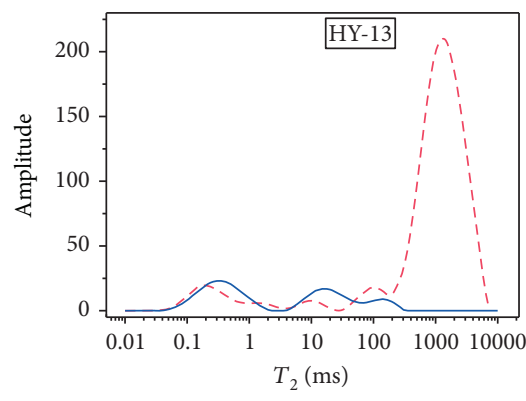

_- Pre-microwave

(l)

Figure 9: Effect of microwave treatment on NMR $T_{2}$ distribution at $S_{\mathrm{w}}$.

would result in coal mechanical strength (such as elasticity modulus) decreasing [53]. Therefore, gas permeability would decrease again with more and more induced fracture. In theory, the microwave energy treatment cannot only induce fractures and increase cleat apertures by thermal expansion but also facilitate coal fracturing by selective heating nature. 


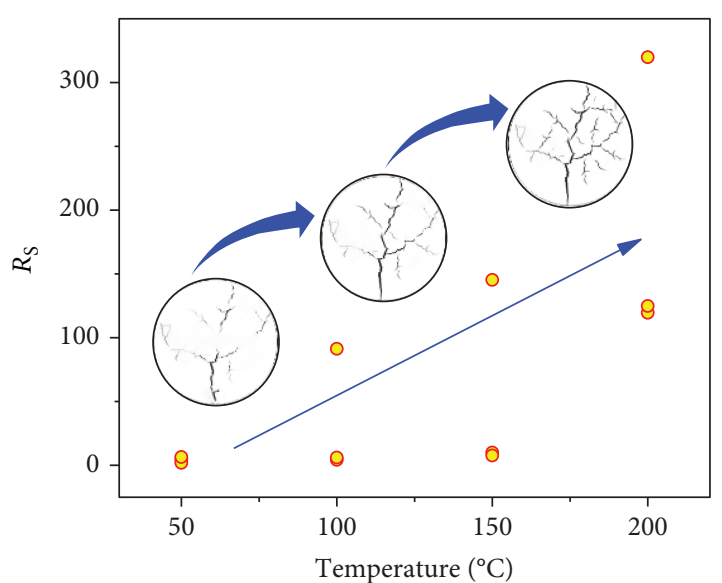

Figure 10: Effect of processing temperature on $R_{\mathrm{s}}$.

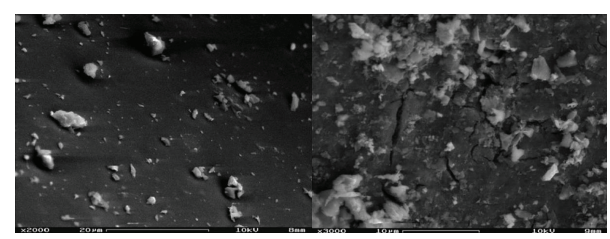

FIGURE 11: Microphotographs of an untreated coke particle (a) and a coke particle subjected to microwave treatment (b) [16].

This is confirmed by Ruisanchez's work [16]. SEM micrographs of the particle microstructure show that the coke particle is more cracked after microwave treatment (Figure 11). Kumar et al. also found the fracture volume of coal increased from $1.8 \%$ to $16.1 \%$ after microwave exposure via microfocused X-ray computed tomography [12]. The coal samples used in this work would maintain pore structure well, which decreases the effect of lateral confining pressure on the pore structure. As discussed in Section 4.2, the specific surface area changed after microwave energy treatment. And the specific surface area influences the gas permeability $[54,55]$. All of these factors induced gas permeability increasing at first and then decreasing with processing temperature increased in this study. This may also suggest that $150^{\circ} \mathrm{C}$ is the optimal processing temperature for improving coal permeability under lateral confining pressure ( $3 \mathrm{MPa}$ and $10 \mathrm{MPa}$ ) in this study.

Fractal dimension, a nonlinear mathematics method initially proposed by Mandelbrot [56], has been extensively employed for quantifying the complexity of structure and physical properties of coal $[57,58]$. Fractal dimension $D$ can be calculated as [22]

$$
D=3-\frac{\ln V_{\mathrm{p}}}{\ln T_{2}-\ln T_{2 \max }},
$$

where $T_{2 \max }$ is transverse relaxation time of the $T_{2}$ spectrum corresponding to maximum pore size; $T_{2}$ is the transverse relaxation time of the $T_{2}$ spectrum corresponding to pore size $r ; V_{\mathrm{p}}$ is the ratio between the whole pore volume that

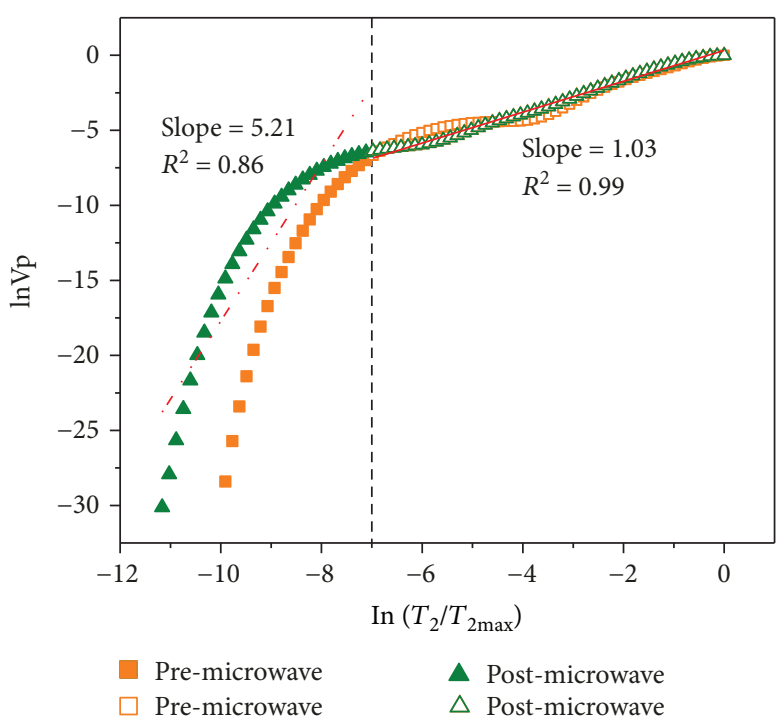

Figure 12: Curve of $\ln \left(V_{\mathrm{p}}\right)$ versus $\ln \left(T_{2} / T_{2 \max }\right)$.

pore size not exceeding $r$ and total pore volume. The prerequisite for the formula is that transverse relaxation time is directly proportional to pore size [59]. The other prerequisite is that maximum $T_{2}$ value is much larger than the minimum $T_{2}$ value exhibited by the medium [59]. In this study, the maximum $T_{2}$ value is fourth orders of magnitude larger than the minimum $T_{2}$ value. The curve of $\ln \left(V_{\mathrm{p}}\right)$ versus $\ln$ $\left(T_{2} / T_{2 \max }\right)$ of the coal core is as shown in Figure 12. And the slope between $\ln \left(V_{\mathrm{p}}\right)$ versus $\ln \left(T_{2} / T_{2 \max }\right)$ is used to calculate the fractal dimension. The value of $\ln \left(V_{\mathrm{p}}\right)$ increased rapidly at first then increased slowly with $\ln \left(T_{2} / T_{2 \max }\right)$ increasing. This turning point is about -7 . So the curve is divided into two parts for linear fitting. It found that the slope of the left part is larger than 3. The fractal dimension calculated from this will be negative. This suggests that the calculated fractal dimension according to the left part curve has less physical meaning. For this reason, the fractal dimension is calculated when $\ln \left(T_{2} / T_{2 \max }\right)$ is larger than -7 in this study.

Fractal dimension decreased after microwave energy treatment (Figure 13(a)). On one hand, the microwave energy treatment would induce fractures in the coal matrix, which would increase the complexity of the pore surface. On the other hand, the microwave treatment may crack pore surface and induce debris. The debris would be taken out during water saturating process. And the pore surface would become smooth. In this study, the second factor may be more obvious. The permeability increased after microwave treatment (Figure 6(a)), and the fractal dimension decreased after microwave treatment (Figure 13(a)). In general, permeability decreases with fractal dimension increasing [60]. However, fractal dimension shows a poor correlation with permeability in this study (Figure 13(b)). This may be due to the following three reasons: (1) the limited number of coal cores brings the inevitable samples errors. (2) The error in the estimated fractal dimension may relate to the assumption $T_{2}$ is directly proportional to pore size. The pore structure of coal is 


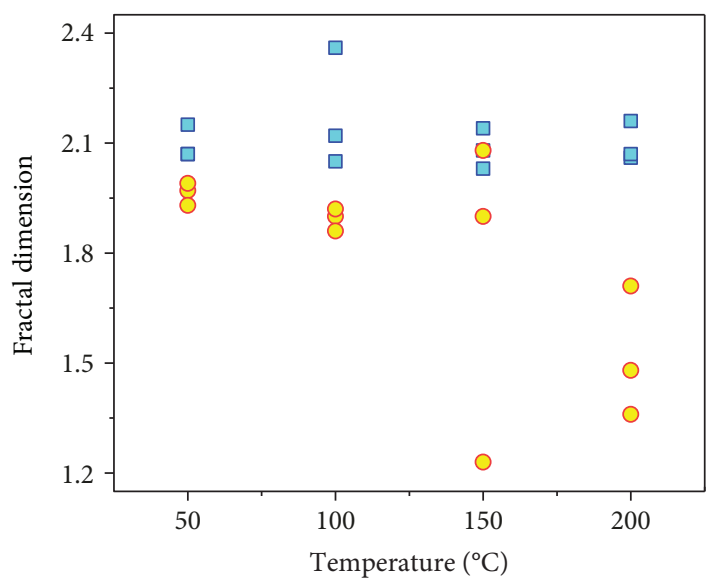

$\square$ Pre-microwave

Post-microwave

(a)

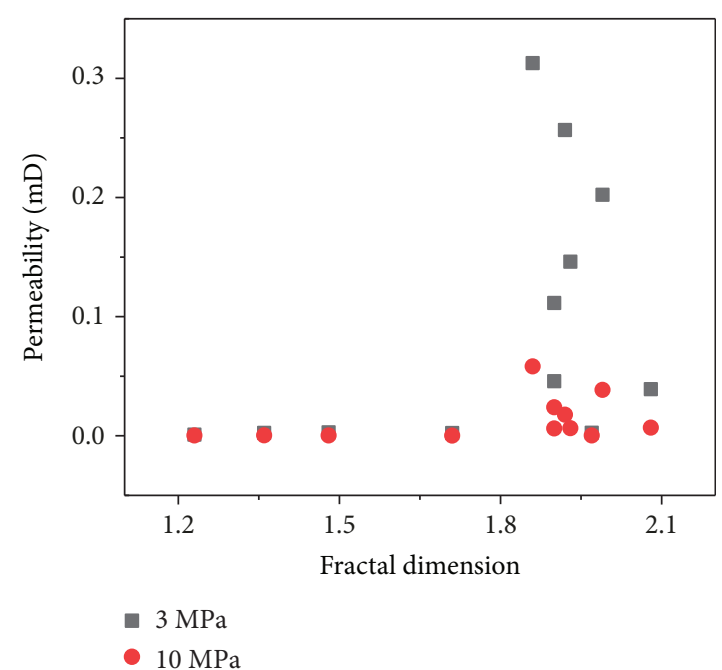

(b)

FIGURE 13: (a) Fractal dimension vs. processing temperature and (b) fractal dimension vs. permeability.

complex and may not fully meet this assumption. (3) The gas permeability is measured by nitrogen; by contrast, the NMR measurement is based on the water in the pore structure. Firstly, molecules size can affect gas transport in coal [61]. Secondly, water may react with clay mineral in pore structure, which would influence the water transport [62]. Thirdly, coal swelling/shrinkage during gas adsorption/ desorption would influence the gas permeability [63]. Therefore, the nitrogen transport in coal is different to the water.

\section{Conclusions}

This study presents the potential use of microwave energy for inducing fractures and increasing cleat apertures in coal cores, which would change pore structure and gas permeability. The coal samples were irradiated with microwave frequency $2.45 \mathrm{GHz}$ and power $6 \mathrm{~kW}$. The nuclear magnetic resonance (NMR) measurements were carried out for evaluating the changing of transverse relaxation time $\left(T_{2}\right)$ distribution of various water saturation degree $\left(S_{\mathrm{w}}>S_{\mathrm{ad}}>S_{\mathrm{ir}}\right)$. The fractal dimension is calculated according to $T_{2}$ distribution. The gas permeability of coal samples was also measured. Major findings are summarized as follows:

(1) The amplitude of $T_{2}$ distribution has a positive relation with water saturation degree, and the water saturation degree has little influence on $T_{2}$ distribution location before microwave treatment. And the area of $T_{2}$ distribution positively relates to the porosity

(2) The location and amplitude of $T_{2}$ distribution has a noticeable relation with water saturation degree after the microwave energy treatment. And MBW model is more suitable to describe the state of bound water in the pore structure

(3) The permeability of coal samples increased after microwave treatment. The gas permeability of coal cores increased at first and then decreased with processing temperature increasing. And the turning point is about $150^{\circ} \mathrm{C}$. In addition, the fractal dimension decreased after microwave energy treatment. However, fractal dimension shows a poor correlation with permeability in this study

\section{Data Availability}

The data used to support the findings of this study are available from the corresponding author upon request.

\section{Conflicts of Interest}

The authors declare that they have no conflicts of interest.

\section{Acknowledgments}

The research is supported by CAS Pioneer Hundred Talents Program (2017-120) and the Open Fund (PLN1502) of the State Key Laboratory of the Oil and Gas Reservoir Geology and Exploitation, Southwest Petroleum University.

\section{References}

[1] T. A. Moore, "Coalbed methane: a review," International Journal of Coal Geology, vol. 101, pp. 36-81, 2012.

[2] H. Dai, Q. Zhao, B. Lin et al., "Premixed combustion of lowconcentration coal mine methane with water vapor addition in a two-section porous media burner," Fuel, vol. 213, pp. 72-82, 2018.

[3] H. Xie, J. Wang, B. Shen et al., "New idea of coal mining: scientific mining and sustainable mining capacity," Journal of China Coal Society, vol. 37, pp. 1069-1079, 2012.

[4] Q. Li, B. Lin, and C. Zhai, "The effect of pulse frequency on the fracture extension during hydraulic fracturing," Journal of Natural Gas Science and Engineering, vol. 21, pp. 296-303, 2014. 
[5] N. Guanhua, L. Baiquan, and Z. Cheng, "Impact of the geological structure on pulsating hydraulic fracturing," A rabian Journal of Geosciences, vol. 8, no. 12, pp. 10381-10388, 2015.

[6] L. B. Colmenares and M. D. Zoback, "Hydraulic fracturing and wellbore completion of coalbed methane wells in the Powder River Basin, Wyoming: implications for water and gas production," AAPG Bulletin, vol. 91, no. 1, pp. 51-67, 2007.

[7] Q. Zou and B. Lin, "Fluid-solid coupling characteristics of gasbearing coal subjected to hydraulic slotting: an experimental investigation," Energy \& Fuels, vol. 32, no. 2, pp. 1047-1060, 2018.

[8] L. Qin, C. Zhai, S. Liu, and J. Xu, "Factors controlling the mechanical properties degradation and permeability of coal subjected to liquid nitrogen freeze-thaw," Scientific Reports, vol. 7, no. 1, p. $3675,2017$.

[9] A. S. Ranathunga, M. S. A. Perera, P. G. Ranjith, Y. Ju, V. Vishal, and P. N. K. de Silva, "A macro-scale experimental study of sub- and super-critical CO2 flow behaviour in Victorian brown coal," Fuel, vol. 158, pp. 864-873, 2015.

[10] A. S. Ranathunga, M. S. A. Perera, and P. G. Ranjith, "Deep coal seams as a greener energy source: a review," Journal of Geophysics and Engineering, vol. 11, no. 6, p. 063001, 2014.

[11] M. Bientinesi, L. Petarca, A. Cerutti et al., "A radiofrequency/ microwave heating method for thermal heavy oil recovery based on a novel tight-shell conceptual design," Journal of Petroleum Science and Engineering, vol. 107, pp. 18-30, 2013.

[12] H. Kumar, E. Lester, S. Kingman et al., "Inducing fractures and increasing cleat apertures in a bituminous coal under isotropic stress via application of microwave energy," International Journal of Coal Geology, vol. 88, no. 1, pp. 75-82, 2011.

[13] W. Zhao, J. Chen, X. D. Chang et al., "Effect of microwave irradiation on selective heating behavior and magnetic separation characteristics of Panzhihua ilmenite," Applied Surface Science, vol. 300, pp. 171-177, 2014.

[14] E. Lester, S. Kingman, and C. Dodds, "Increased coal grindability as a result of microwave pretreatment at economic energy inputs," Fuel, vol. 84, no. 4, pp. 423-427, 2005.

[15] B. K. Sahoo, S. De, and B. C. Meikap, "Improvement of grinding characteristics of Indian coal by microwave pretreatment," Fuel Processing Technology, vol. 92, no. 10, pp. 1920-1928, 2011.

[16] E. Ruisanchez, A. Arenillas, E. J. Juarez-Perez, and J. A. Menendez, "Pulses of microwave radiation to improve coke grindability," Fuel, vol. 102, pp. 65-71, 2012.

[17] J.-Z. Liu, J.-F. Zhu, J. Cheng, J.-H. Zhou, and K.-F. Cen, "Pore structure and fractal analysis of Ximeng lignite under microwave irradiation," Fuel, vol. 146, pp. 41-50, 2015.

[18] X. Q. Zhao, B. W. Guo, W. L. Wang et al., "Experimental study on microwave pyrolysis of three Chinese lignite," Journal of Analytical and Applied Pyrolysis, vol. 124, pp. 303-309, 2017.

[19] L. C. Ge, Y. W. Zhang, Z. H. Wang, J. H. Zhou, and K. F. Cen, "Effects of microwave irradiation treatment on physicochemical characteristics of Chinese low-rank coals," Energy Conversion and Management, vol. 71, pp. 84-91, 2013.

[20] W. Wang, F. Xin, Y. Tu, and Z. Wang, "Pore structure development in Xilingol lignite under microwave irradiation," Journal of the Energy Institute, vol. 91, no. 1, pp. 75-86, 2018.

[21] Y. D. Hong, B. Q. Lin, C. J. Zhu, and H. Li, "Effect of microwave irradiation on petrophysical characterization of coals," Applied Thermal Engineering, vol. 102, pp. 1109-1125, 2016.
[22] Y. D. Hong, B. Q. Lin, C. J. Zhu, and H. Li, "Influence of microwave energy on fractal dimension of coal cores: implications from nuclear magnetic resonance," Energy \& Fuels, vol. 30, no. 12, pp. 10253-10259, 2016.

[23] M. S. A. Perera, P. G. Ranjith, S. K. Choi, and D. Airey, "Investigation of temperature effect on permeability of naturally fractured black coal for carbon dioxide movement: an experimental and numerical study," Fuel, vol. 94, pp. 596-605, 2012.

[24] Z. Yangsheng, Q. Fang, W. Zhijun, Z. Yuan, L. Weiguo, and M. Qiaorong, "Experimental investigation on correlation between permeability variation and pore structure during coal pyrolysis," Transport in Porous Media, vol. 82, no. 2, pp. 401$412,2010$.

[25] Z. Li, X. Xian, and Q. Long, "Experiment study of coal permeability under different temperature and stress," Journal of China University of Mining and Technology, vol. 38, pp. 523527, 2009.

[26] Z. Feng, Z. Wan, Y. Zhao et al., "Experimental study of permeability of anthracite and gas coal masses under high temperature and triaxial stress," Chinese Journal of Rock Mechanics and Engineering, vol. 29, pp. 689-696, 2010.

[27] S. Wu, D. Tang, S. Li, H. Wu, X. Hu, and X. Zhu, "Effects of geological pressure and temperature on permeability behaviors of middle-low volatile bituminous coals in eastern Ordos Basin, China," Journal of Petroleum Science and Engineering, vol. 153, pp. 372-384, 2017.

[28] H. Li, B. Lin, W. Yang, Y. Hong, and Z. Wang, "A fully coupled electromagnetic-thermal-mechanical model for coalbed methane extraction with microwave heating," Journal of Natural Gas Science and Engineering, vol. 46, pp. 830-844, 2017.

[29] B. Lin, H. Li, Z. Chen, C. Zheng, Y. Hong, and Z. Wang, "Sensitivity analysis on the microwave heating of coal: a coupled electromagnetic and heat transfer model," Applied Thermal Engineering, vol. 126, pp. 949-962, 2017.

[30] Y. D. Cai, D. M. Liu, Y. B. Yao, Z. T. Li, and Z. J. Pan, "Partial coal pyrolysis and its implication to enhance coalbed methane recovery, part I: an experimental investigation," Fuel, vol. 132, pp. 12-19, 2014.

[31] Y. Yao, D. Liu, Y. Che, D. Tang, S. Tang, and W. Huang, "Petrophysical characterization of coals by low-field nuclear magnetic resonance (NMR)," Fuel, vol. 89, no. 7, pp. 1371$1380,2010$.

[32] D. Xuan, S. Fu, and R. Xie, "Study on NMR logging bulk volume of irreducible water model," Nuclear Electronics \& Detection Technology, vol. 27, no. 3, pp. 578-582, 2007.

[33] Y. He, Z. Mao, L. Xiao, and X. Ren, "An improved method of using NMR $\mathrm{T}_{2}$ distribution to evaluate pore size distribution," Chinese Journal of Geophysics, vol. 48, pp. 373-378, 2005.

[34] N. Golsanami, J. Sun, and Z. Zhang, "A review on the applications of the nuclear magnetic resonance (NMR) technology for investigating fractures," Journal of Applied Geophysics, vol. 133, pp. 30-38, 2016.

[35] A. S. Khorshidi, J. Storsley, L. N. Malunga, S. J. Thandapilly, and N. Ames, "Advancing the science of wheat quality evaluation using nuclear magnetic resonance (NMR) and ultrasound-based techniques," Cereal Chemistry, vol. 95, no. 3, pp. 347-364, 2018.

[36] M. F. Marcone, S. Wang, W. Albabish, S. Nie, D. Somnarain, and A. Hill, "Diverse food-based applications of nuclear 
magnetic resonance (NMR) technology," Food Research International, vol. 51, no. 2, pp. 729-747, 2013.

[37] N. Zhang, F. Zhao, P. Guo et al., "Nanoscale pore structure characterization and permeability of mudrocks and finegrained sandstones in coal reservoirs by scanning electron microscopy, mercury intrusion porosimetry, and low-field nuclear magnetic resonance," Geofluids, vol. 2018, 20 pages, 2018.

[38] S. Li, D. Tang, Z. Pan, H. Xu, and W. Huang, "Characterization of the stress sensitivity of pores for different rank coals by nuclear magnetic resonance," Fuel, vol. 111, pp. 746-754, 2013.

[39] R. L. Kleinberg, C. Straley, W. E. Kenyon, R. Akkurt, and S. A. Farooqui, "Nuclear magnetic resonance of rocks: $\mathrm{T}_{1}$ vs. $\mathrm{T}_{2}$," in SPE Annual Technical Conference and Exhibition, p. 11, Houston, TX, USA, 1993.

[40] G. R. Coates, L. Xiao, and M. G. Prammer, NMR Logging Principles and Applications, Halliburton Energy Services, Houston, TX, USA, 1999.

[41] R. L. Kleinberg, "Utility of NMR $\mathrm{T}_{2}$ distributions, connection with capillary pressure, clay effect, and determination of the surface relaxivity parameter $\rho_{2}$," Magnetic Resonance Imaging, vol. 14, no. 7-8, pp. 761-767, 1996.

[42] C. Han, Study on Simultaneous Iterative Reconstruction Technique Inversion Method of NMR Relaxation Signal, Jilin University, 2014.

[43] Z. Lv, "Study on the connectivity of pore structure of coal in three-dimensional space," in Proceedings 2011 International Conference on Computer Distributed Control and Intelligent Environmental Monitoring (CDCIEM 2011), pp. 1797-1799, Changsha, China, (2011).

[44] Y. Meng, Z. Li, and F. Lai, "Experimental study on porosity and permeability of anthracite coal under different stresses," Journal of Petroleum Science and Engineering, vol. 133, pp. 810-817, 2015.

[45] Y. Yao, D. Liu, J. Liu, and S. Xie, “Assessing the water migration and permeability of large intact bituminous and anthracite coals using NMR relaxation spectrometry," Transport in Porous Media, vol. 107, no. 2, pp. 527-542, 2015.

[46] S. Marland, B. Han, A. Merchant, and N. Rowson, "The effect of microwave radiation on coal grindability," Fuel, vol. 79, no. 11, pp. 1283-1288, 2000.

[47] M. S. Seehra, A. Kalra, and A. Manivannan, "Dewatering of fine coal slurries by selective heating with microwaves," Fuel, vol. 86, no. 5-6, pp. 829-834, 2007.

[48] J. Pan, Y. Zhao, Q. Hou, and Y. Jin, "Nanoscale pores in coal related to coal rank and deformation structures," Transport in Porous Media, vol. 107, no. 2, pp. 543-554, 2015.

[49] H. Li, B. Lin, W. Yang et al., "Experimental study on the petrophysical variation of different rank coals with microwave treatment," International Journal of Coal Geology, vol. 154-155, pp. 82-91, 2016.

[50] D. Prinz, W. Pyckhout-Hintzen, and R. Littke, “Development of the meso- and macroporous structure of coals with rank as analysed with small angle neutron scattering and adsorption experiments," Fuel, vol. 83, no. 4-5, pp. 547-556, 2004.

[51] T. T. Chau, "A review of techniques for measurement of contact angles and their applicability on mineral surfaces," Minerals Engineering, vol. 22, no. 3, pp. 213-219, 2009.
[52] M. Li, The Research on Pyrolysis-Penetration and Microstructure of Lignite, Taiyuan University of Technology, Taiyuan, China, 2012.

[53] Y. Wang, M. Li, B. Chen, and S. Dai, "Experimental study on ultrasonic wave characteristics of coal samples under dry and water saturated conditions," Journal of China Coal Society, vol. 40, pp. 2445-2450, 2015.

[54] M. Zambrano, E. Tondi, L. Mancini et al., "Fluid flow simulation and permeability computation in deformed porous carbonate grainstones," Advances in Water Resources, vol. 115, pp. 95-111, 2018.

[55] M. Zambrano, E. Tondi, L. Mancini et al., "3D Pore-network quantitative analysis in deformed carbonate grainstones," Marine and Petroleum Geology, vol. 82, pp. 251-264, 2017.

[56] B. B. Mandelbrot, The Fractal Geometry of Nature, Macmillan, 1983.

[57] W. I. Friesen and R. J. Mikula, "Fractal dimensions of coal particles," Journal of Colloid and Interface Science, vol. 120, no. 1, pp. 263-271, 1987.

[58] W. Chengyang, H. Shixiong, S. Wenjing, and C. Wei, "Fractal dimension of coal particles and their $\mathrm{CH}_{4}$ adsorption," International Journal of Mining Science and Technology, vol. 22, no. 6, pp. 855-858, 2012.

[59] H. Daigle, A. Johnson, and B. Thomas, "Determining fractal dimension from nuclear magnetic resonance data in rocks with internal magnetic field gradients," Geophysics, vol. 79, no. 6, pp. D425-D431, 2014.

[60] Y. B. Yao, D. M. Liu, D. Z. Tang et al., "Fractal characterization of seepage-pores of coals from China: an investigation on permeability of coals," Computers \& Geosciences, vol. 35, no. 6, pp. 1159-1166, 2009.

[61] X. J. Cui, R. M. Bustin, and G. Dipple, "Selective transport of $\mathrm{CO}_{2}, \mathrm{CH}_{4}$, and $\mathrm{N}_{2}$ in coals: insights from modeling of experimental gas adsorption data," Fuel, vol. 83, no. 3, pp. 293-303, 2004.

[62] J. Sun, Z. Yang, H. Guo, Q. Xiao, M. Hao, and X. Xu, “Comparative study of tight reservoir permeability using steady-state and unsteady-state methods," Rock and Soil Mechanics, vol. 34, pp. 1009-1016, 2013.

[63] Z. Pan and L. D. Connell, "Modelling of anisotropic coal swelling and its impact on permeability behaviour for primary and enhanced coalbed methane recovery," International Journal of Coal Geology, vol. 85, no. 3-4, pp. 257-267, 2011. 

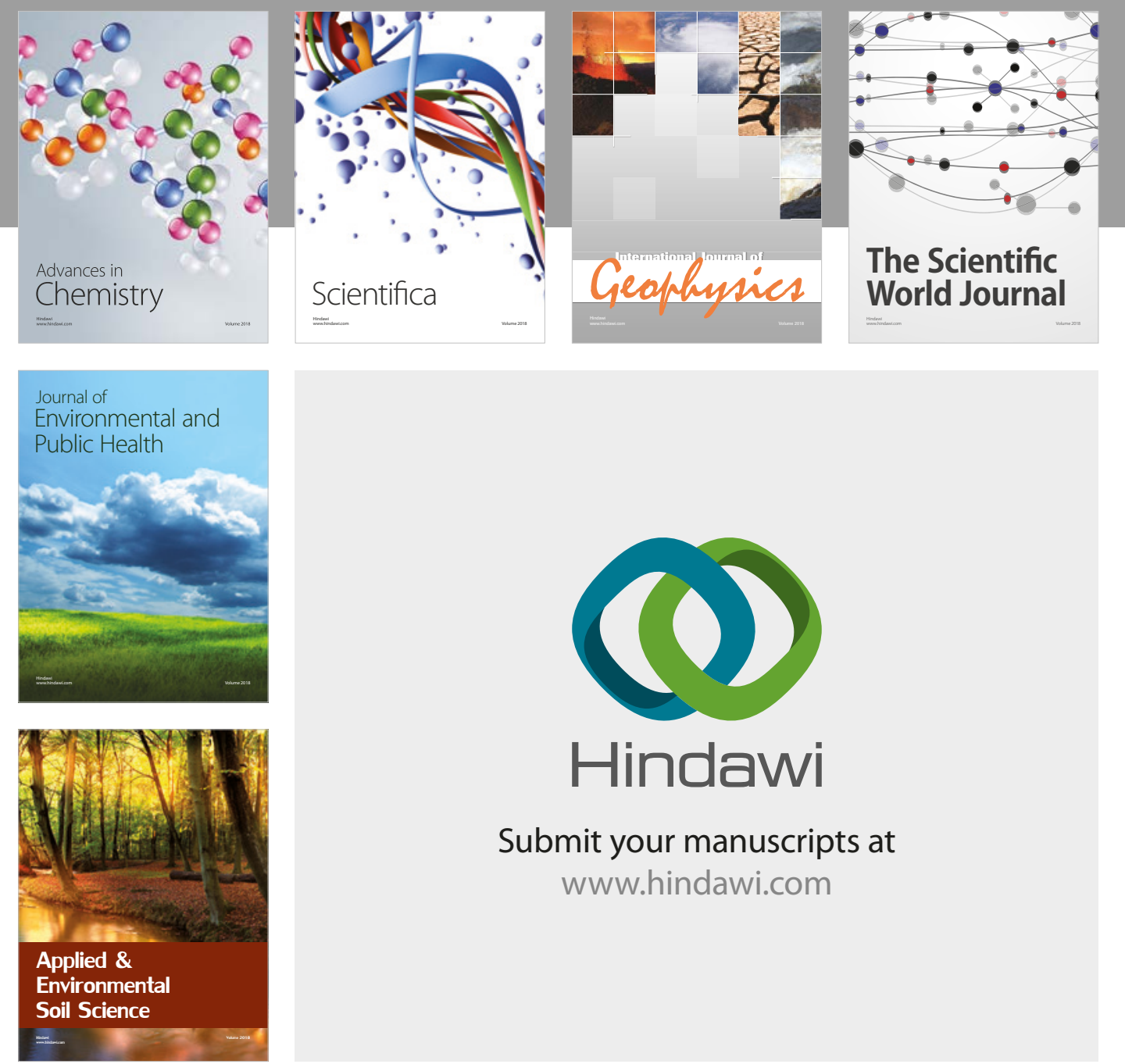

The Scientific

\section{World Journal}
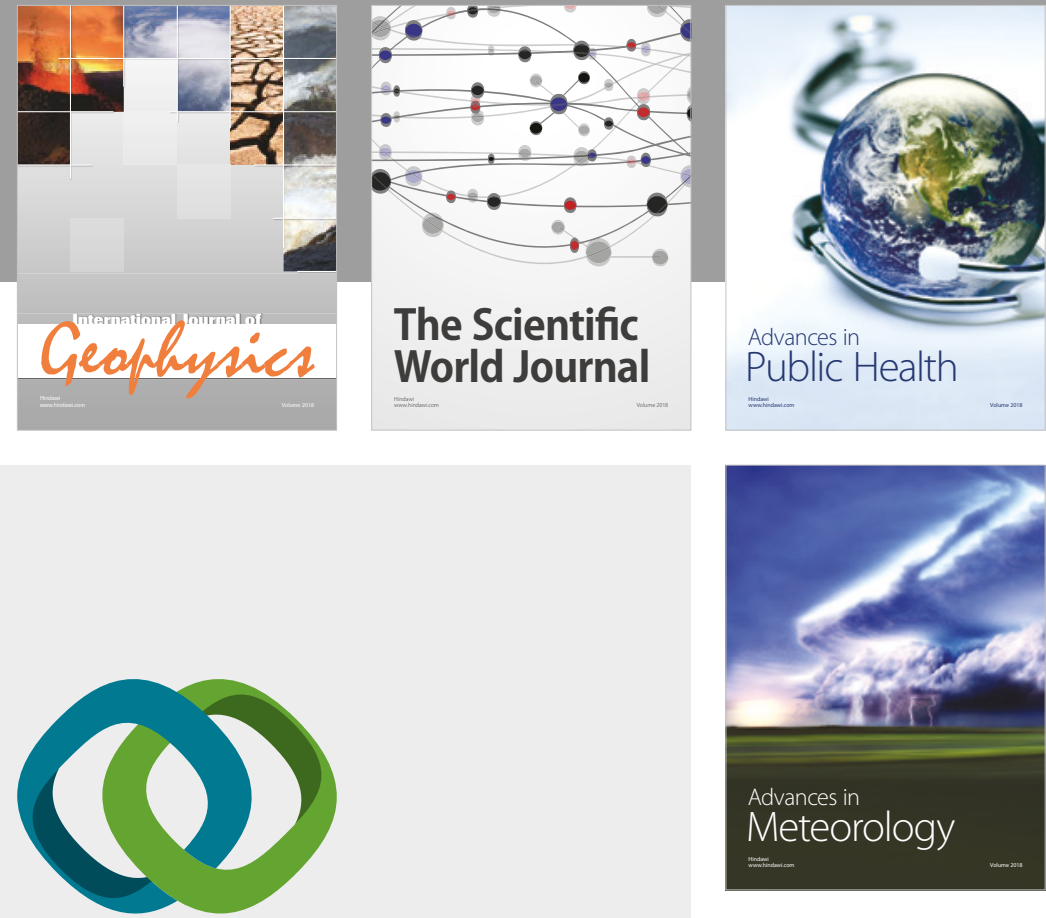

Advan

Public Health

\section{Hindawi}

Submit your manuscripts at

www.hindawi.com
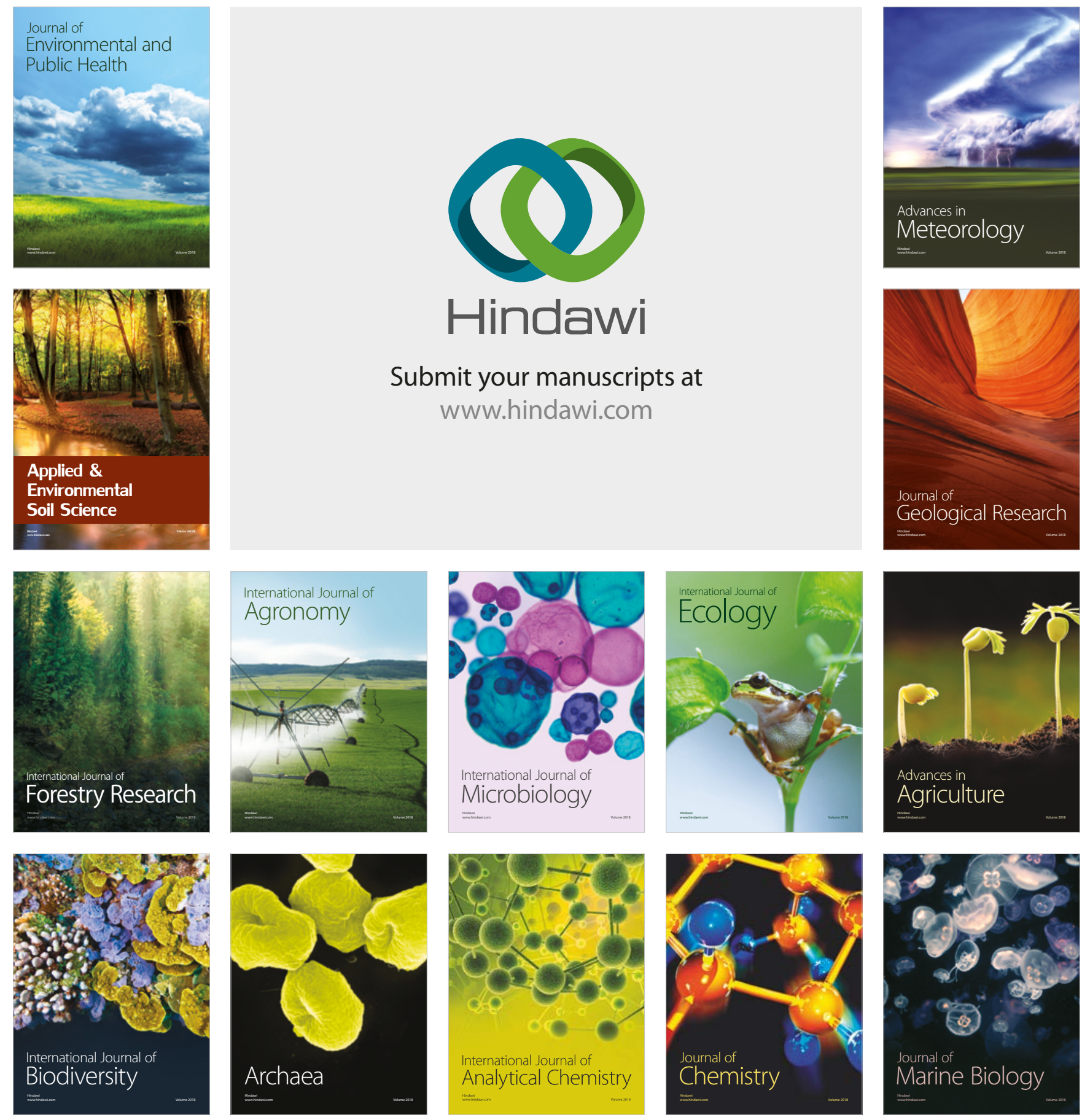